\title{
Analisis Pengaruh Cap Tip (Electrode Tips) terhadap Sisa Spatter Spot Area Body Shop PT. Isuzu Motor Indonesia Plant Karawang
}

\section{The Analysis of the Effect of Electrode Tips on Spatter Spot in the Body Shop Area of PT. Isuzu Motor Indonesia Plant, Karawang}

\author{
Rianita Puspa Sari ${ }^{1 *}$, Dene Herwanto ${ }^{2}$, Ana Suryana ${ }^{3}$ \\ 1,2,3 Program Studi Teknik Industri, Universitas Singaperbangsa Karawang, Jl. H. S. Ronggowaluyo, \\ Telukjambe Timur, Karawang 41361, Indonesia \\ *e-mail: rianita.puspasari@ft.unsika.ac.id
}

Received: June 29, 2017; Revised: July 18, 2017; Accepted: August 7, 2017

\begin{abstract}
ABSTRAK
Body Shop terdiri dari area proses produksi perakitan sub item atau komponen yang kemudian disatukan pada pembuatan cabin mobil yang sebagian besar menggunakan bahan dasar material pelat logam dengan menggunakan metode pengelasan resistensi listrik atau Spot Welding. Spot Welding dapat dilakukan dengan menggunakan elektroda dengan nama lain CAP TIP (Elecrode Tips), yang terbuat dari paduan tembaga di aliri arus listrik yang cukup besar, dalam waktu yang relatif singkat. Proses penyambungan material kemudian menimbulkan percikan api (spatter) yang mana ditemukannya sisa spatter spot pada bagian pelat cabin. Penelitian ini bertujuan untuk menganalisa pengaruh CAP TIP (electrode tips) terhadap sisa spatter spot yang terdapat pada cabin mobil dengan menggunakan metode ANOVA. Data survei diperoleh dari 3 jenis CAP TIP (PG 1712, PG 1431, PG 1777-50) dari 10 jenis CAP TIP yang digunakan pada area body shop beserta jumlah sisa spatter yang dihasilkan. Hasil penelitian mengungkapkan adanya kesamaan varian dari ketiga jenis yang telah dibandingkan dari nilai levene statistic sebesar 1.563, dengan rata-rata jumlah sisa spatter terbanyak dihasilkan oleh jenis CAP TIP PG 1712 sebanyak 47.17,sedangkan nilai F sebesar 0.914 dengan signifikansi 0.443 yang mengindikasikan tidak terdapat perbedaan jenis CAP TIP yang signifikan terhadap sisa spatter, maka $\mathrm{H}_{0}$ ditolak. Hal ini membuktikan bahwa tidak adanya pengaruh CAP TIP (electrode tips) terhadap sisa spatter spot.
\end{abstract}

Kata Kunci: Electrode tips, Welding spot, Spatter spot, ANOVA

\begin{abstract}
Body Shop consists of the assembly production process area of sub items or components combined with car cabin manufactured mostly using the base material of metal plate by using electric welding resistance method or Spot Welding. Spot Welding can be done by using an electrode with another name CAP TIP (Electrode Tips), made of copper alloy run by a large electric current, in a relatively short time. The grafting material process generates spatter. The spatter spots are discovered on the cabin plane. This study aims to analyze the effect of CAP TIP (electrode tips) on the remaining spatter spot found on car cabin using ANOVA method. The survey data were obtained from 3 types of CAP TIP (PG 1712, PG 1431, PG 1777-50) of 10 types of CAP TIP used in the body shop area along with the amount of residual spatter produced. The results revealed variant similarity of the three types compared from the Levene statistic value of 1,563, with the average number of residual spatter most produced by CAP TIP PG 1712 as 47.17, while the $F$ value of 0.914 with the significance of 0.443 indicating no significant CAP TIP type difference against the rest of the spatter, thus $H_{0}$ is rejected. This proves that there is no effect of CAP TIP (electrode tips) on the remaining spatter spots.
\end{abstract}

Keywords: Electrode tips, Welding spot, Spatter spot, ANOVA

http://journal.ubm.ac.id/index.php/jiems |97 


\section{PENDAhULUAN}

\subsection{Latar Belakang}

Dalam proses manufaktur, kegiatan pengelasan merupakan kegiatan yang tidak dapat dipisahkan untuk assembling, Salah satu jenis pengelasan adalah spot welding atau las resistansi listrik. Pengelasan Resistansi merupakan salah satu proses pengelasan listrik tertua yang digunakan saat ini (Miller, 2012). Menurut Wiryosumarto (2008) spot welding merupakan salah satu cara pengelasan resistansi listrik, dimana dua atau lebih lembaran logam dijepit di antara dua elektroda. Kemudian arus yang kuat dialirkan melalui elektroda tembaga, sehingga titik diantara pelat logam dibawah elektroda yang saling bersinggungan menjadi panas akibat resistansi listrik hingga mencapai suhu pengelasan, dan mengakibatkan kedua pelat pada bagian ini menyatu. (Hendrawan, 2011).

Spot welding merupakan salah satu cara pengelasan resistansi listrik, dimana permukaan pelat yang disambung ditekankan satu sama lain dan pada saat yang sama arus listrik dialirkan sehingga permukaan tersebut menjadi panas dan mencair karena adanya restansi listrik. (Wiryosumarto dan Okumura, 2008). Menurut Miller (2012) pengelasan resistansi dilakukan saat arus melalui CAP TIP (Elecrode Tips) dan potongan logam yang terpisah untuk digabungkan.

Body Shop merupakan bagian alur produksi yang mana secara garis besar bagian dari Divisi Plan yang membawahi daerah produksi salah satunya Body Painting Operation. Pada Body Shop terdiri dari area proses produksi perakitan sub item atau komponen yang kemudian disatukan pada pembuatan cabin mobil yang sebagian besar menggunakan bahan dasar material logam pelat dengan menggunakan metode pengelasan resistensi listrik atau spot welding.

Hendrawan (2011) menyatakan spot welding dapat dilakukan dengan atau tanpa menggunakan elektroda dengan nama lain CAP TIP (Elecrode Tips), yang terbuat dari paduan tembaga di aliri arus listrik yang cukup besar, dalam waktu yang relatif singkat. Proses penyambungan material kemudian menimbulkan percikan api (spatter) yang mana ditemukannya sisa spatter pada bagian pelat cabin.

Miller (2012) menyatakan dalam pengelasan CAP TIP (Electrode Tips) memiliki tujuan untuk melakukan pengelasan arus ke benda kerja, menjadi titik fokus tekanan yang diterapkan pada sambungan las, dan untuk melakukan panas dari permukaan kerja. CAP TIP (Electrode Tips) harus menjaga integritas bentuk dan karakteristik pengelasan, konduktivitas termal dan listrik di bawah kondisi kerja.

Penelitian Aji (2004) membuktikan bahwa Spatter yang terlalu besar akan memberikan dampak yang merugikan dalam performance proses produksi dan kualitas produk yang dihasilkan. Spatter merupakan loncatan bunga api yang muncul sebagai bagian dari proses spot welding.

Hasil penelitian Kusano (2011) membuktikan bahwa produksi body mobil untuk menggunakan pengelasan resistensi termasuk spot welding menjadi sesuatu hal yang wajar, pada saat pengulangan proses pengelasan akan menyebabkan kerusakan hingga patah pada CAP TIP (Electrode Tips) dan akan menimbulkan masalah pada pelat body, maka diperlukan manajemen electrode dengan tip dressing yang memiliki unggulan tidak hanya pada penghematan biaya namun juga mengurangi spatter tanpa harus meningkatkan arus.

Pada area body shop terdapat sisa spatter pada pelat mobil, setiap lini dari proses assembling menggunakan jenis ukuran CAP TIP (Elecrode Tips) yang berbeda, Miller (2012) menyatakan ukuran CAP TIP (Elecrode Tips) mengontrol ukuran las resistensi spot, salah satu permasalahan spatter dapat disebabkan ketidak-sesuaian ukuran dan kesejajaran pada tip. Oleh karena itu pada penelitian ini bertujuan untuk melakukan analisis pengaruh CAP TIP (Elecrode Tips) terhadap sisa spatter spot area body shop PT. Isuzu Astra Motor Indonesia. Ukuran Cap Tip yang berbeda dapat menyebabkan spatter pada cabin mobil, pengaruh sisa spatter ini akan berkaitan dengan SQDMP (Safety, Quality, Delivery, Moral, Productivity) dalam 
menunjang Visi dan Misi PT. Isuzu Astra Motor Indonesia untuk menjadi nomor satu bisnis commercial vehicle truck bermesin diesel di pasar Indonesia dan terus menerus meningkatkan dan mempromosikan poduk hericle truck di Indonesia melalui kepuasan pelanggan. Selain itu, pengaruh $\mathrm{C}$

\subsection{Ruang Lingkup Penelitian}

Penelitian ini dilakukan pada BPO (Body Shop Operation) di PT. Isuzu Astra Motor Indonesia plant Karawang dengan memproduksi mobil Comerial Vericle (CV). BPO (Body Shop Operation) memiliki dua divisi produksi yaitu body shop yang proses assembling item part menjadi cabin dengan proses pengelasan seperti welding gun, las $\mathrm{CO}_{2}$ dan pedestal dan painting shop pada proses pewarnaan pada cabin. Pengambilan data dilakukan pada body shop dilaksanakan selama 1 bulan terhitung dari tanggal 01 Februari s/d 28 Februari 2017.

\section{METODOLOGI}

Pada penelitian ini, acuan yang dipakai untuk membuat metodologi penelitian adalah kerangka berpikir yang dikembangkan oleh Sekaran (2006). Proses penelitian ini secara garis besar dibagi ke dalam empat tahapan, yaitu tahap pendahuluan, perancangan kerangka kerja teoretis, pengumpulan dan pengolahan data, hingga tahap analisis dan penarikan kesimpulan. Gambar 1 menjelaskan alur diagram metodologi penelitian.

Dalam mengumpulkan data, metode yang dipakai peneliti adalah pencarian data primer mengenai jenis-jenis CAP TIP apa saja yang digunakan oleh perusahaan dalam proses spot welding. Setelah mengetahui jenis CAP TIP yang digunakan kemudian mengambil data jumlah sisa spatter pada area body shop. Pengolahan data dilakukan dengan menggunakan metode-metode statistika, ANOVA digunakan untuk mengetahui apakah CAP TIP yang digunakan pada saat proses spot welding memengaruhi jumlah sisa spatter pada area body shop. Data yang telah lengkap kemudian dilakukan pengujian validitas dan reliabilitas, apabila data tersebut lolos uji, maka data akan segera diolah. Namun, apabila data tidak lolos uji, maka di asumsikan adanya kesalahan dalam pengambilan data sehingga data harus diambil kembali.

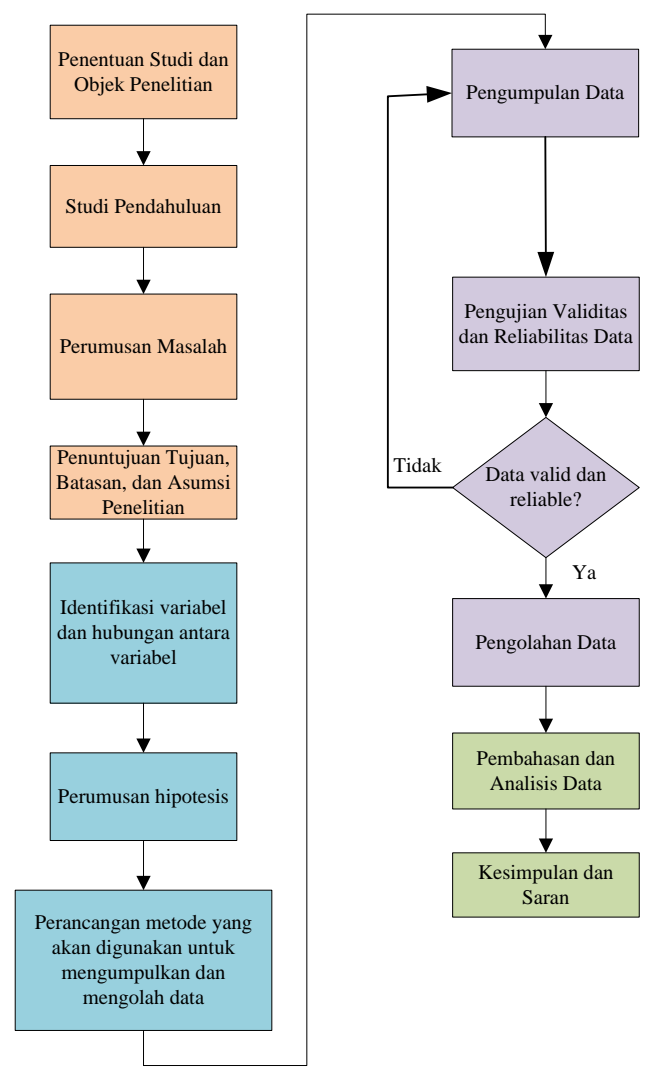

Gambar 1. Flowchart Metodologi Penelitian

Sahota et al., (2013) melakukan analisis pengaruh parameter terhadap material resistance spot weld dengan menggunakan ANOVA, untuk mengidentifikasi parameter yang signifikan pada respon karakteristik material.

Menurut Sarwono (2015), Prosedur ANOVA satu faktor akan menghasilkan analisis satu fakor untuk sebuah variabel tergantung dengan sebuah variabel bebas. Kegunaan utama teknik ini ialah untuk menguji hipotesis yang membuktikan ratarata sama atau tidak.

Penelitian ini, melakukan pengamatan menggunakan fishbone diagram dengan menggunakan indikator 4M (Manusia, Metode, Material dan Mesin) untuk mengetahui penyebab sisa spatter. Selain itu, untuk melakukan analisis pengaruh CAP TIP (Elecrode Tips) terhadap sisa spatter spot 
area body shop menggunakan metodologi ANOVA.

\section{HASIL DAN PEMBAHASAN}

Data yang diperoleh dari pengambilan data secara langsung, kemudian diuji validitas dan reliabilitas agar dapat digunakan pengolahan data lebih lanjut. Hasil uji validitas dan reliabilitas menggunakkan SPSS 21.0 menunjukkan bahwa data telah valid dan reliabel.

Identifikasi penyebab adanya spatter dilakukan peneliti dengan membuat diagram fishbone, yang dapat dilihat pada Gambar 2.

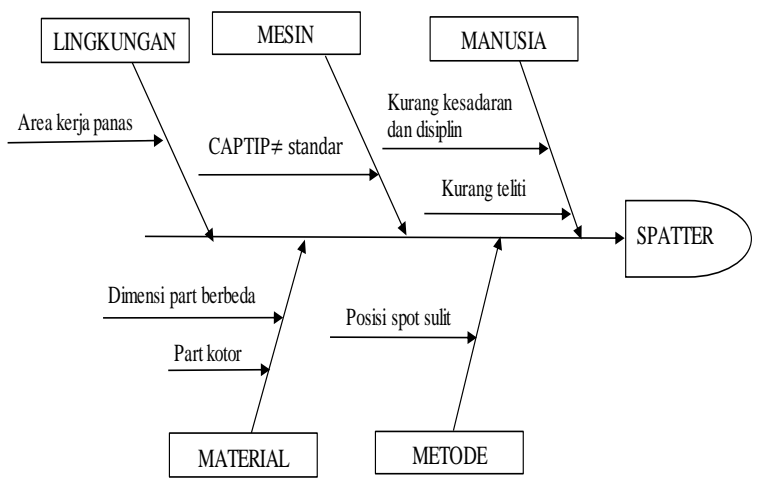

Gambar 2. Diagram Fishbone

Dari Gambar 2 dapat diketahui bahwa faktor mesin sangat berpengaruh pada spatter. Maka pemecahan masalah akan fokus pada faktor mesin yang bersumber dari CAP TIP (Electrode Tips). Pemilihan mesin pada diagram fishbone berlanjut pada pengumpulan data, sehingga menjadi pembahasan lebih lanjut terhadap CAP TIP (Electrode Tips). Sampel diambil sebanyak 3 jenis dari 10 jenis CAP TIP (Electrode Tips) yang ada berdasarkan hasil pengamatan pada bagian body shop PT. Isuzu Astra Motor Indonesia.
Data yang terdapat dari diagram fishbone selanjutnya akan di analisa untuk mengetahui perbandingan banyaknya spatter yang dihasilkan dari 3 jenis CAP TIP pada Body Shop PT. Isuzu Astra Motor Indonesia. Dari 5 (lima) faktor dalam diagram fishbone dilakukan pendekatan dengan melihat dari sisi lain dari CAP TIP (Electrode Tips) dalam mencari pengaruh dari sisa spatter diantaranya:

1. CAP TIP (Electrode Tips) Jenis PG $1712 \mathrm{~A}$

2. CAP TIP (Electrode Tips) Jenis PG 1431

3. CAP TIP (Electrode Tips) Jenis PG 177750

Pengumpulan data dilakukan selama 6 hari sebagai sampel untuk menentukan perbandingan dengan menggunakan metode ANOVA (Analysis of Variance), Adapun data yang didapatkan pada Tabel 1, sedangkan hasil pengolahan data ANOVA menggunakan SPSS 21.0 pada Gambar 3 .

Pada Gambar 3 mengindikasikan perbedaan rata-rata jumlah sisa spatter dari 3 jenis CAP TIP dengan rincian sebagai berikut:

a. Rata-rata CAP TIP PG 1712 yaitu 47,17

b. Rata-rata CAP TIP PG 1431 yaitu 29,33

c. Rata-rata CAP TIP PG 1777-50 yaitu 27,50

Maka rata-rata jumlah sisa spatter terbanyak ialah CAP TIP PG 1712 A.

Tabel 1. Data Spatter

\begin{tabular}{cccc}
\hline \multirow{2}{*}{ Hari } & \multicolumn{3}{c}{ Jenis CAP TIP } \\
\cline { 2 - 4 } & PG 1712 A & PG 1431 & PG 1777-50 \\
\hline 1 & 125 & 67 & 33 \\
2 & 55 & 34 & 15 \\
3 & 38 & 26 & 58 \\
4 & 18 & 11 & 24 \\
5 & 23 & 21 & 10 \\
6 & 24 & 17 & 25 \\
\hline
\end{tabular}

Sumber: Hasil Pengamatan (2017)

Descriptives

Jumlah

\begin{tabular}{|c|c|c|c|c|c|c|c|c|}
\hline & \multirow[b]{2}{*}{$\mathrm{N}$} & \multirow[b]{2}{*}{ Mean } & \multirow[b]{2}{*}{ Std. Deviation } & \multirow[b]{2}{*}{ Std. Error } & \multicolumn{2}{|c|}{$\begin{array}{l}95 \% \text { Confidence Interval for } \\
\text { Mean }\end{array}$} & \multirow[b]{2}{*}{ Minimum } & \multirow[b]{2}{*}{ Maximum } \\
\hline & & & & & Lower Bound & Upper Bound & & \\
\hline PG 1712 A & 6 & 47,1667 & 40,43472 & 16,50741 & 4,7330 & 89,6003 & 18,00 & 125,00 \\
\hline PG 1431 & 6 & 29,3333 & 20,04661 & 8,18400 & 8,2957 & 50,3710 & 11,00 & 67,00 \\
\hline PG $1777-50$ & 6 & 27,5000 & 16,97940 & 6,93181 & 9,6812 & 45,3188 & 10,00 & 58,00 \\
\hline Total & 18 & 34,6667 & 27,69795 & 6,52847 & 20,8928 & 48,4405 & 10,00 & 125,00 \\
\hline
\end{tabular}

Gambar 3. Pengolahan data ANOVA 


\section{Test of Homogeneity of Variances}

Jumlah

\begin{tabular}{|c|r|r|r|}
\hline $\begin{array}{l}\text { Levene } \\
\text { Statistic }\end{array}$ & df1 & \multicolumn{1}{c|}{ df2 } & Sig. \\
\hline 1,563 & 2 & 15 &, 242 \\
\hline
\end{tabular}

Gambar 4. Uji Homogen Varian

Merumuskan Hipotesis:

$\mathrm{H}_{0}$ : Varian ketiga jumlah sisa sppater jenis CAP TIP sama

$\mathrm{H}_{1}$ : Varian ketiga jumlah sisa sppater jenis CAP TIP tidak sama

Dari Gambar 4, diperoleh angka Levene Statistic sebesar 1,563 dengan signifikansi/probabilitas (sig) sebesar 0,242. Karena angka signifikansi/probabilitas hitung > 0,05 (0,242 > 0,05); maka $\mathrm{H}_{0}$ diterima dan $\mathrm{H}_{1}$ ditolak. Dengan melakukan pengolahan data yang membandingkan varian ketiga jenis CAP TIP (Electrode Tips) uji homogen varian adalah sama. Maka sampai saat ini sudah memenuhi persyaratan pokok, yaitu adanya kesamaan varian dari ketiga jenis yang telah dibandingkan. Dengan demikian, analisa dapat dilanjutkan pada bagian berikutnya karena persyaratan pokok penggunaan prosedur ANOVA telah terpenuhi.

Berdasarkan Gambar 5, diperoleh nilai probabilitas/signifikansi sebesar 0,422 . Oleh karena nilai probabilitas/signifikansi $0,442>0,05$. Maka hipotesis diatas tidak terdapat perbedaan jenis CAP TIP yang signifikan terhadap sisa spatter. Nilai $F$ hitung sebesar 0,914 sedangkan nilai $\mathrm{F}$ tabel sebesar 3,29, karena, nilai $\mathrm{F}$ hitung pada Gambar 6 berada pada wilayah penerimaan $\mathrm{H}_{0}$ maka, $\mathrm{H}_{0}$ diterima artinya jenis CAP TIP tidak berpengaruh terhadap sisa spatter.

Analisis hasil diatas menunjukkan bahwa jumlah sisa spatter terbanyak ada pada jenis CAP TIP PG 1712 A. Namun, setelah dilakukan uji ANOVA ketiga varian CAP TIP di atas tidak memberikan pengaruh yang signifikan pada sisa spatter.

ANOVA

Jumlah
\begin{tabular}{|l|r|r|r|r|r|}
\hline & $\begin{array}{l}\text { Sum of } \\
\text { Squares }\end{array}$ & df & Mean Square & \multicolumn{1}{c|}{ F } & Sig. \\
\hline Between Groups & 1416,333 & 2 & 708,167 &, 914 &, 422 \\
Within Groups & 11625,667 & 15 & 775,044 & & \\
Total & 13042,000 & 17 & & & \\
\hline
\end{tabular}

Gambar 5. Hasil Uji ANOVA

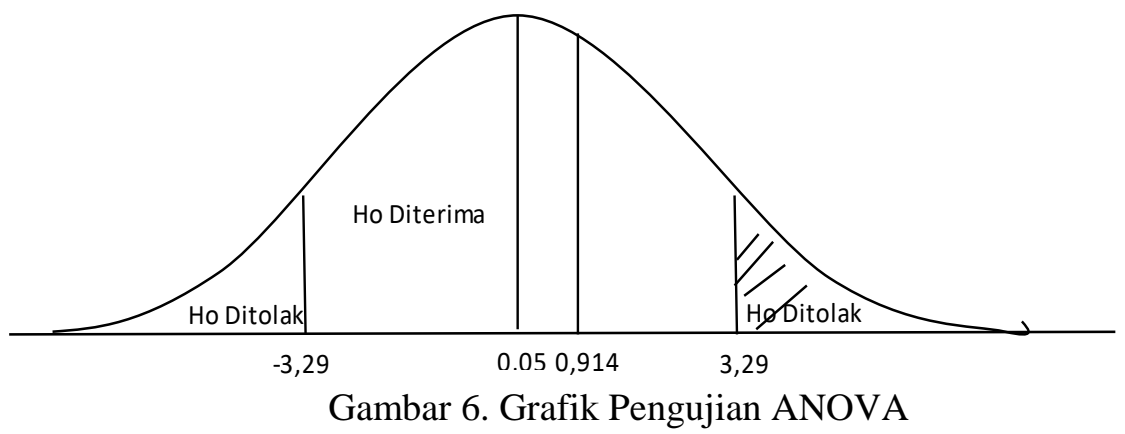




\section{KESIMPULAN}

Welding spot merupakan salah satu cara pengelasan resistansi listrik, dimana dua atau lebih lembaran logam dijepit oleh CAP TIP di antara dua elektroda. CAP TIP (Electrode Tips) memiliki tujuan untuk melakukan pengelasan arus ke benda kerja, menjadi titik fokus tekanan yang diterapkan pada sambungan las, dan untuk melakukan panas dari permukaan kerja. CAP TIP (Electrode Tips) harus menjaga integritas bentuk dan karakteristik pengelasan, konduktivitas termal dan listrik di bawah kondisi kerja. ukuran CAP TIP (Elecrode Tips) mengontrol ukuran las resistensi spot, salah satu permasalahan spatter dapat disebabkan ukuran dan kesejajaran pada tip yang tidak sesuai.

Pada penelitian ini, hasil dari metode ANOVA, bahwa nilai F hitung 0,914 dengan signifikan 0.422 menyatakan hipotesis diatas tidak terdapat perbedaan jenis CAP TIP yang signifikan terhadap sisa spatter walau CAP tip yang digunakan perusahaan memiliki ukuran yang berbeda, selain itu nilai $F$ hitung berada pada wilayah penerimaan $\mathrm{H}_{0}$ maka, $\mathrm{H}_{0}$ diterima artinya jenis CAP TIP pada perusahaan tidak berpengaruh terhadap sisa spatter.

Hasil penelitian ini membuktikan bahwa spatter tidak dipengaruhi secara signifikan oleh CAP TIP (electrode tips). Pada penelitian selanjutnya diharapkan perlu dilakukan penelitian mengenai hal-hal lain yang dapat mempengaruji spatter, misal ketebalan pelat, kondisi permukaan pelat sudah dibersihkan atau tidak, maupun pengaturan paramater proses pada mesin Spot Welding (Voltage/Current/time).

\section{DAFTAR PUSTAKA}

Aji, L.W (2004). "Analisa hasil proses Spot Welding pada JIG front door s/a inner no.1 tipe gun KDX35-3558-16N dengan aplikasi kondisi welding low spatter pada PT.Astra Daihatsu Motor”. Skripsi Universitas Indonesia.

Hendrawan, A.M (2011). "Studi Komparasi Kualitas Produk Pengelasaan Welding Spot Dengan Pendinginan Dan Non-Pendinginan Elektroda". Prosiding Seminar Nasional Sains dan Teknologi ke-2, Fakultas Teknik Universitas Wahid Hasyim Semarang, Vol.2 pp. C.48C.53.

Kusano. H. (2011)." Electrode Dressing Makes a Better Spot Weld". Welding Journal, Paper The AWS Detroit Section's Sheet Metal Welding Conference XIV, Livonia, Vol.XIV pp.28-32.

Miller. (2012). Handbook For Resistance Spot Welding. USA: Miller Eletric Mfg. Co., 1llinois.

Sahota, D.S., Ramandeep S., Rajesh S., dan Harpreet S. (2013). "Study of Effect of Parameters on Resistance Spot Weld of ASS316 Material". Mechanica Confab Vol.2 No.2 FebruaryMarch 2013 pp.67-78, ISSN: 2320-2491.

Sarwono, J. (2015). Rumus-rumus Populer Dalam SPSS 22 Untuk Riset Skripsi. Yogyakarta: Andi Offset.

Sekaran. U. (2006): Research Methods for Business, John Wiley

Wiryosumarto, H. dan Okumura, T. (2008). Teknologi Pengelasan Logam. Jakarta: PT.Balai Pustaka. 